Part 2 provides a satisfactory introduction to organic chemistry, a special feature being the number of large and well-printed structural formulæ. The non-specialist is helped by the omission of detailed descriptions of preparations and properties, although this commendable feature is rather marred by the naming of too many complex organic compounds.

The section on the chemistry of foods, Part 3, should be of particular interest at the present time to both scientific worker and layman because the relative values of various foodstuffs are compared. The chemistry of digestion is explained, as also are some of the mysteries of the kitchen. An elementary account is given of the vitamins, and this includes an interesting table of an adult's requirements of vitamins and the weights of different foodstuffs containing these quantities. Inciden- tally, the figures in the table refer to the daily requirement of an adult, but the author has omitted to mention this fact.

The final section of the book, Part 4, gives a simple but interesting survey of industrial chemistry. The sources and methods of obtaining the raw materials are first described, and then elementary details are given of the chemical processes whereby these raw materials are made to yield metals, acids, ceramics, refined oils, etc.

This volume, which is printed in large type and strongly bound, should prove a valuable addition to any library. The intelligent layman and the sixth-form pupil on the non-science side will find much of interest in the book, while chemistry teachers will find useful material in it for the preparation of their general science courses.

A. C. C.

\title{
MEASUREMENT OF TEMPERATURE
}

\section{A Manual of Heat and Temperature Measurement \\ Compiled by Robert L. Weber. Pp. vii +141 . (Ann Arbor, Mich.: Edwards Brothers, Inc., 1939.) 2.85 dollars.}

\section{Temperature Measurement}

By Robert L. Weber. Pp. $x+172$. (Ann Arbor, Mich.: Edwards Brothers, Inc., 1941.) 2.50 dollars.

THE interest of these volumes lies chiefly in
the light which they throw on the methods
adopted in a progressive American university to
give a practical course to those who will after-
wards use scientific instruments in their work.
Each book is in two parts, the first an outline of
the subject, the second giving the laboratory
notes for about twenty experiments.

In the manual of heat and temperature measurement, Part 1 would strike an English student as far too scrappy to be of any value except for revision : in twelve chapters, of an average length of 6 or 7 pages each, the subject of heat is dealt with. Chapter iv, on the other hand, occupying 15 pages (including a full-page photograph of the outside of a potentiometer indicator), compensates for these defects by giving a much fuller, helpful and critical account of thermocouples and their uses than would be found in a British text-book. Subsequent chapters deal sketchily with the theory and well with the practice of radiation pyrometry and resistance thermometry. There are very good chapters indeed on recording pyrometers and on automatic control of temperature
Part 2 of either volume would offer suggestions to many teaching institutions. The whole outlook is practical, and the experiments are well chosen to illustrate principles and yet to introduce the student to instruments likely to be used in his subsequent career.

The later book, on the other hand, deals more thoroughly with its less extensive subject. The outlook is admirably practical, and there are tabbles of the properties of thermo-electric metals and of refractories, in addition to other data which make the book of value to the worker in heat, as well as to those in the student stage. All branches of temperature measurement-including the extremely low and the extremely high-are considered, and such matters as flame temperature are not overlooked.

The books have been photographically reproduced from typescript, presumably with the figures gummed on to the copy, and the result is pleasing. They are bound in a limp cloth which seems likely to withstand student handling, and would well repay perusal, if not by students, at any rate by those who plan their courses of instruction. Many of the figures lack any informative value, and some are too dark to show any detail, but a pair on p. 101 of the later work, showing interference fringes caused by heated streams of air, are magnificent.

In each book there is an appendix of tables, larger in the 1941 book than in its predecessor, noteworthy among them being a compact table of the E.M.F. of thermocouples every $2^{\circ}$ from $0^{\circ}$ to as high as $1720^{\circ} \mathrm{C}$, and occupying no more than a page. 